\title{
Different role of MSLN and CA125 co-expression as a prognostic predictor between perihilar and distal bile duct carcinoma
}

\author{
YASUHIRO TAKIHATA ${ }^{1}$, TAKAHIRO EINAMA ${ }^{1}$, KAZUKI KOBAYASHI ${ }^{1}$, TAKAFUMI SUZUKI ${ }^{1}$, \\ NAOTO YONAMINE ${ }^{1}$, IBUKI FUJINUMA ${ }^{1}$, TAKAZUMI TSUNENARI ${ }^{1}$, YOJI YAMAGISHI ${ }^{1}$, \\ TOSHIMITSU IWASAKI ${ }^{1}$, YOICHI MIYATA ${ }^{1}$, EIJI SHINTO ${ }^{1}$, SHO OGATA $^{2}$, \\ HIRONORI TSUJIMOTO $^{1}$, HIDEKI UENO ${ }^{1}$ and YOJI KISHI $^{1}$ \\ Departments of ${ }^{1}$ Surgery and ${ }^{2}$ Pathology and Laboratory Medicine, \\ National Defense Medical College, Tokorozawa, Saitama 359-8513, Japan
}

Received December 11, 2020; Accepted February 15, 2021

DOI: $10.3892 / \mathrm{ol} .2021 .12675$

\begin{abstract}
Recent studies have suggested that the interaction of mesothelin (MSLN) and cancer antigen 125 (CA125) enhances tumor metastases. The aim of the present study was to clarify the impact of MSLN and CA125 co-expression on the prognosis of patients with extrahepatic bile duct carcinoma (BDC). Tissue samples from patients who underwent surgical resection between 2007 and 2015 for perihilar or distal BDC were immunohistochemically examined. The expression levels of MSLN and CA125 in tumor cells were analyzed. The expression in $<50 \%$ and $\geq 50 \%$ of the total tumor cells were defined as low- and high-level expression, respectively. Tissue samples were obtained from 31 patients with perihilar BDC and 43 patients with distal BDC. Lymph node metastases were associated with MSLN and CA125 co-expression in patients with perihilar $\mathrm{BDC}(\mathrm{P}=0.002)$, while there was no association between lymph node metastasis and co-expression in patients with distal BDC $(\mathrm{P}=0.362)$. MSLN and CA125 co-expression was associated with a worse overall survival rate in patients with perihilar BDC (5-year overall survival rate, co-expression positive vs. negative, 24 vs. $63 \% ; \mathrm{P}=0.038$ ). To the best of our knowledge, the present study is the first to report an association between co-expression of MSLN and CA125 with a poor prognosis in patients with perihilar BDC. The current findings suggested that the significance of co-expression differed according to the $\mathrm{BDC}$ location.
\end{abstract}

Correspondence to: Dr Takahiro Einama, Department of Surgery, National Defense Medical College, 3 Chome-2 Namiki, Tokorozawa, Saitama 359-8513, Japan

E-mail: einama0722@ndmc.ac.jp

Abbreviations: BDC, bile duct carcinoma; MSLN, mesothelin; CA125, cancer antigen 125

Key words: cholangiocarcinoma, BDC, MSLN, CA125

\section{Introduction}

Bile duct carcinoma (BDC) consists of heterogenous groups of neoplasia according to their location. Extrahepatic BDC has been divided into perihilar and distal BDC (1). The two subtypes are regarded as separate entities because of differences in their epidemiology, clinical management, and prognosis (2-5). However, the histopathological differences have not been clarified.

Mesothelin (MSLN) is a 40-kDa cell surface glycoprotein, which is expressed in normal mesothelial cells that line the surface of the pleura, pericardium, and peritoneum $(6,7)$. Overexpression of MSLN in various types of malignant tumors, including malignant mesothelioma, ovarian cancer, and pancreatic cancer has been reported (8-11). The full-length human MSLN gene encodes primarily a 71-kDa precursor protein. It can be physiologically cleaved by several furin-like proteases into a membrane-bound 40-kDa C-terminal fragment and a $31-\mathrm{kDa} \mathrm{N}$-terminal fragment, and the latter is secreted into the blood. The former fragment is MSLN, which is attached to the cell membrane through a glycosyl-phosphatidylinositol anchor $(7,12)$.

MSLN is one of the binding partners of cancer antigen 125 (CA125) (13-15). Previous studies showed that heterotypic adhesion through the high affinity interaction between MSLN and CA125 could facilitate peritoneal metastases of ovarian cancer $(13,15)$. Other studies $(16,17)$ showed that expression of MSLN in patients with extrahepatic BDC and intrahepatic cholangiocellular carcinoma was associated with poor prognosis. However, no studies have evaluated the incidence of MSLN and CA125 co-expression in patients with extrahepatic BDC. The aim of this study was to evaluate the differences in the incidence of co-expression between perihilar and distal BDC patients and the impact of CA125 and MSLN expression on prognosis.

\section{Materials and methods}

Ethics approval and consent to participate. This study was performed in accordance with the Declaration of Helsinki and was approved by the institutional review board of the National 
Defense Medical College (approval no. 4115). All patients agreed to participate in this study, and written informed consent was obtained from all patients.

Tumor specimens. Tissue samples taken from patients who underwent surgical resection for perihilar or distal BDC from January 2007 to December 2015 were immunohistochemically examined. Pathological $\mathrm{T}$ and $\mathrm{N}$ factors and Stage were recorded according to the 8th edition of the Union for International Cancer Control (UICC) staging (1).

Immunohistochemistry. Formalin-fixed paraffin-embedded tissue blocks were collected. Immunohistochemistry (IHC) was performed on tumor samples using monoclonal antibodies against MSLN (clone 5B2 diluted 1:50; Leica Biosystems Newcastle Ltd.) and CA125 (clone M11 Ready-to-Use; Agilent Technologies Inc.) at room temperature for $60 \mathrm{~min}$. Next, samples were incubated with Histofine (Simple Stain MAX PO (MULTI); Nichirei Biosciences Inc.) at room temperature for $30 \mathrm{~min}$. Specific antigen-antibody reactions were visualized with diaminobenzidine tetrahydrochloride and hydrogen peroxide (Liquid DAB+ Substrate Chromogen System; Agilent Technologies Inc.). Slides were counterstained with hematoxylin for $1.5 \mathrm{~min}$, then rinsed gently in reagent quality water for $10 \mathrm{~min}$.

Immunohistochemical evaluation. All histological assessments were performed on the tumor region of the specimen with magnification, $\mathrm{x} 200$. Each slide was independently evaluated by three observers (Y.T., Y.Y. and T.E.) who were blinded to the clinical outcomes. Discrepancies among the investigators were resolved by consensus using a multiheaded microscope. Immunostaining for MSLN and CA125 was evaluated for the proportion of tumor cells stained in each case. The levels of MSLN and CA125 expression were assessed as the number of stained tumor cells divided by the total number of tumor cells on the largest cross-sectioned slice of the tumor and were classified as follows: $0 \%$ to $<50 \%$ and $\geq 50 \%$ (Fig. 1). The proportional expression levels in the tumor, $<50 \%$ and $\geq 50 \%$, were defined as low- and high-level expression, respectively. We defined the positive co-expression as the expression of both MSLN and CA125 in $\geq 50 \%$ of the tumor cells.

Statistical analysis. We used the Chi-squared $\left(\chi^{2}\right)$ test or Fisher's exact test to determine the association of MSLN and CA125 co-expression with clinicopathological data. All numerical data were compared by independent samples t-test. Survival curves of patients were drawn using the Kaplan-Meier method. Differences in survival curves were analyzed by the $\log$-rank test. Statistical significance was defined as $\mathrm{P}<0.05$ for all analyses. Excel Statistics $2012^{\circledR}$ software package (SSRI) was used for statistical analyses.

\section{Results}

Specimen selection. Tissue samples were obtained from 31 patients with perihilar BDC and 43 patients with distal BDC. The patients' clinicopathological characteristics are summarized in Table I. There were no significant differences in the distribution of age, sex, incidence of lymph node metastases, and proportion of patients who received adjuvant chemotherapy between the two groups. Conversely, the distribution of T category and stage, types of surgical procedure, and $\mathrm{R}$ status differed significantly.

MSLN and CA125 expression in perihilar or distal BDC. High-level expression of MSLN and CA125 was detected in 21 specimens $(68 \%)$ and 18 specimens $(58 \%)$, respectively, from perihilar BDC, and in 26 specimens (60\%) and 28 specimens (65\%), respectively, from distal BDC. Fisher's exact test indicated the association between these two expressions in perihilar BDC $(\mathrm{P}=0.036)$ and in distal $\mathrm{BDC}(\mathrm{P}=0.046)$ (Fig. 2).

Tables II and III show the comparison of pathological features according to the expression of MSLN and CA125 in patients with perihilar and distal BDC, respectively. In the perihilar BDC group, lymph node metastases were more frequently observed in patients with MSLN high-level expression $(\mathrm{P}=0.060), \mathrm{CA} 125$ high-level expression $(\mathrm{P}=0.014)$, and co-expression ( $\mathrm{P}=0.002)$. Blood vessel permeation $(\mathrm{P}=0.064)$ and neural invasion $(\mathrm{P}=0.064)$ were more frequently observed in patients with high-level CA125 expression. In the distal BDC group, neural invasion was more frequently observed in patients with MSLN high-level expression $(\mathrm{P}=0.055)$ and CA125 high-level expression ( $\mathrm{P}=0.037)$. However, co-expression of MSLN and CA125 was not associated with any of the evaluated clinicopathological factors.

Survival analyses. Fig. 3 shows survival curves of the patients with and without MSLN and CA125 co-expression. Overall survival was significantly different in the patients with perihilar BDC (5-year survival rate, co-expression negative vs. positive, 63 vs. $24 \%, \mathrm{P}=0.038$ ), while it was comparable in the patients with distal BDC (5-year survival rate, co-expression negative vs. co-expression positive, 56 vs. $46 \%, \mathrm{P}=0.726$ ).

\section{Discussion}

In this study, we demonstrated that high-level co-expression of MSLN and CA125 was observed in nearly half of the patients either with perihilar (48\%) or distal BDC (47\%). However, our results showed that co-expression was associated with lymph node metastases and worse prognosis only in the patients with perihilar BDC.

MSLN expression has been shown to promote tumorigenesis and metastasis via lymphatic invasion of cancer both in vitro and in vivo (18). Clinicopathologically, MSLN expression was associated with lymph node metastases in patients with gastric cancer (19) and colorectal cancer (20). To date, few studies have addressed MSLN expression in extrahepatic BDC. Kawamata et al (16) showed that MSLN high-level expression in extrahepatic BDC was associated with a high incidence of liver metastases and worse survival rates, while there was no association between MSLN expression and lymph node metastases. However, their study included BDC from various locations as follows: hilar, 16 cases; upper, 17 cases; middle, 20 cases; lower, 8 cases. We evaluated perihilar and distal BDC separately because they were different in the types of surgical procedure used or peritumor environment. In fact, our study showed that there is a difference in the association of MSLN or CA125 expression with clinicopathological features 
Table I. Clinicopathological characteristics of 74 patients with perihilar $(n=31)$ or distal $(n=43)$ BDC.

\begin{tabular}{|c|c|c|c|c|}
\hline Parameter & Total, $\mathrm{n}$ & Perihilar BDC & Distal BDC & P-value \\
\hline Median age (range), years & & $72(38-86)$ & $70(42-88)$ & 0.654 \\
\hline \multicolumn{5}{|l|}{ Sex, n (\%) } \\
\hline Male & 54 & $20(37)$ & $34(63)$ & \multirow[t]{2}{*}{0.164} \\
\hline Female & 20 & $11(55)$ & $9(45)$ & \\
\hline \multicolumn{5}{|l|}{ pT stage UICC, n (\%) } \\
\hline pT1-2 & 51 & $16(31)$ & $35(69)$ & \multirow[t]{2}{*}{0.006} \\
\hline pT3-4 & 23 & $15(65)$ & $8(35)$ & \\
\hline \multicolumn{5}{|l|}{ pN stage UICC, n (\%) } \\
\hline $\mathrm{pN} 0$ & 27 & $11(41)$ & $16(59)$ & \multirow[t]{2}{*}{0.879} \\
\hline pN1-2 & 47 & $20(43)$ & $27(57)$ & \\
\hline \multicolumn{5}{|l|}{ Pathological stage UICC, n (\%) } \\
\hline I-II & 41 & $8(20)$ & $33(80)$ & \multirow[t]{2}{*}{$<0.001$} \\
\hline III-IV & 33 & $23(70)$ & $10(30)$ & \\
\hline \multicolumn{5}{|l|}{ Surgical procedure, n (\%) } \\
\hline $\begin{array}{l}\text { Extended right or left hepatectomy } \\
\text { with bile duct resection }\end{array}$ & 25 & $25(100)$ & $0(0)$ & \multirow[t]{4}{*}{$\mathrm{NC}$} \\
\hline Extrahepatic bile duct resection & 1 & $1(100)$ & $0(0)$ & \\
\hline $\begin{array}{l}\text { Subtotal stomach-preserving } \\
\text { pancreaticoduodenectomy }\end{array}$ & 37 & $1(2)$ & $36(98)$ & \\
\hline $\begin{array}{l}\text { Hepatectomy and } \\
\text { pancreaticoduodenectomy }\end{array}$ & 11 & $4(36)$ & $7(64)$ & \\
\hline \multicolumn{5}{|l|}{ Residual tumor, n (\%) } \\
\hline R0 & 40 & $12(30)$ & $28(70)$ & \multirow[t]{2}{*}{0.025} \\
\hline $\mathrm{R} 1$ & 34 & $19(56)$ & $15(44)$ & \\
\hline \multicolumn{5}{|l|}{ Recurrence, $\mathrm{n}(\%)$} \\
\hline Yes & 40 & $20(50)$ & $20(50)$ & \multirow[t]{2}{*}{0.125} \\
\hline No & 34 & $11(32)$ & $23(68)$ & \\
\hline \multicolumn{5}{|l|}{ Adjuvant chemotherapy, n (\%) } \\
\hline Yes & 11 & $4(36)$ & $7(64)$ & \multirow[t]{2}{*}{0.477} \\
\hline No & 63 & $27(43)$ & $36(57)$ & \\
\hline
\end{tabular}

${ }^{a} \geq 3$ segments. Data analyzed via Fisher's exact test (for parameters with expected values of $<5$ in $>20 \%$ of cells) or $\chi^{2}$ test or unpaired t-test (for age). BDC, bile duct carcinoma; UICC, Union for International Cancer Control; pT stage, pathological tumor stage; pN stage, pathological lymph node stage; $\mathrm{NC}$, not calculated.

between perihilar and distal BDC. Our results suggested that biological features of BDC might differ between the two subgroups.

Some papers indicated the differences for lymph node metastasis between perihilar and distal BDC. Wang et al (21) reported that distant lymph node metastasis was commonly seen in perihilar BDC, not in distal BDC. Hasebe et al (22) reported that nodal tumors with more than 4 mitotic figures significantly increased the hazard ratios of tumor recurrence and initial distant organ metastasis in the perihilar portion. Moreover, Noji et al (23) showed that incidence of extra capsular lymph node involvement in perihilar BDC was significantly lower than in the distal BDC. These findings supported that lymph node metastasis showed different pathological features between the perihilar and distal BDC. In this study, co-expression of MSLN and CA125 was associated with lymph node metastasis in perihilar BDC, not in distal BDC. These results suggested that the mechanism of lymph node metastasis might be different in perihilar and distal BDC.

A previous study showed that MSLN and CA125 co-expression was an independent predictor of poor survival in patients with pancreatic ductal adenocarcinoma (PDAC) (11). Shimizu et al (24) showed that there is an interaction between MSLN and CA125 by immunoprecipitation assay and revealed that they were observed only in infiltrating components of PDAC and increased at the invasion front by immunohistochemical analysis. Chen et al (25) demonstrated that the interaction of MSLN and CA125 markedly enhanced motility and invasion of pancreatic cancer cells via selective induction of matrix metalloproteinase (MMP)-7. Further, they reported that the MSLN-CA125 interaction might induce pancreatic cancer cell motility and invasion via a p38 MAPK-dependent pathway. 
A Perihilar bile duct carcinoma
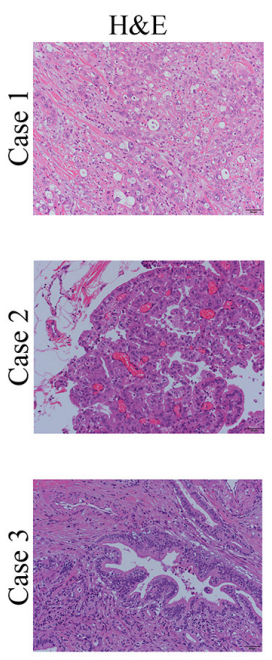

MSLN



High

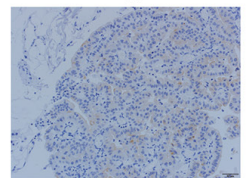

High

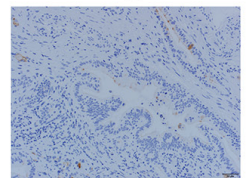

Low

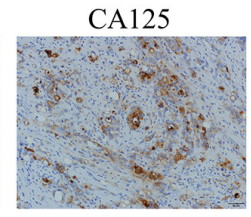

High

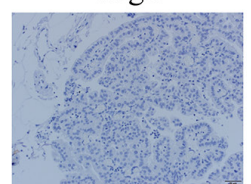

Low

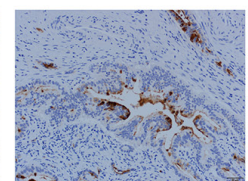

High
B Distal bile duct carcinoma
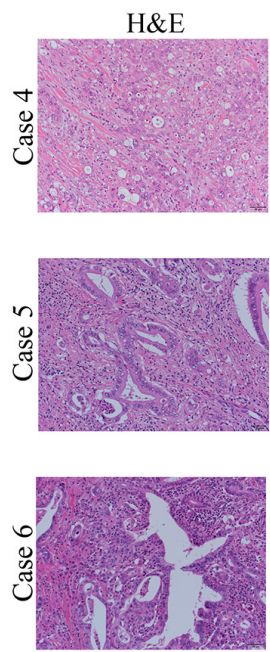

High

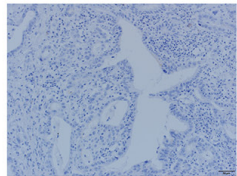

Low

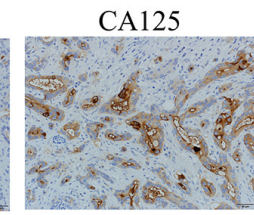

High
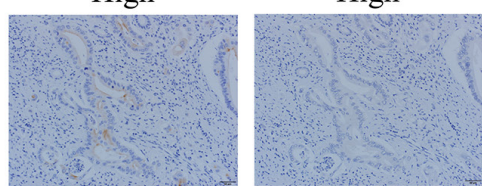

Low

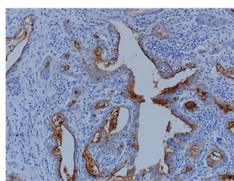

High

Figure 1. Representative cases of (A) perihilar or (B) distal bile duct carcinoma showing H\&E staining, MSLN and CA125 expression. Cases 1 and 4 represent MSLN and CA125 high-level expression. Cases 2 and 5 represent MSLN high-level expression and CA125 low-level expression. Cases 3 and 6 represent MSLN low-level expression and CA125 high-level expression. Magnification, x200. H\&E, hematoxylin and eosin; MSLN, mesothelin; CA125, cancer antigen 125.
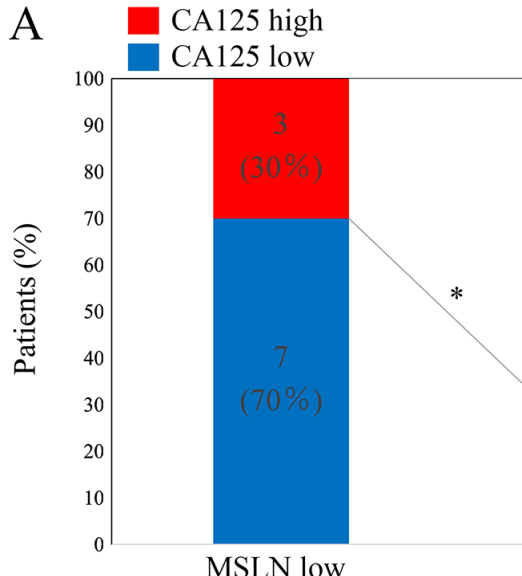

MSLN low
$* \mathrm{P}=0.036$

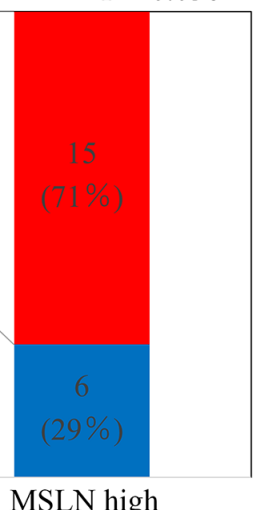

B CA125 high

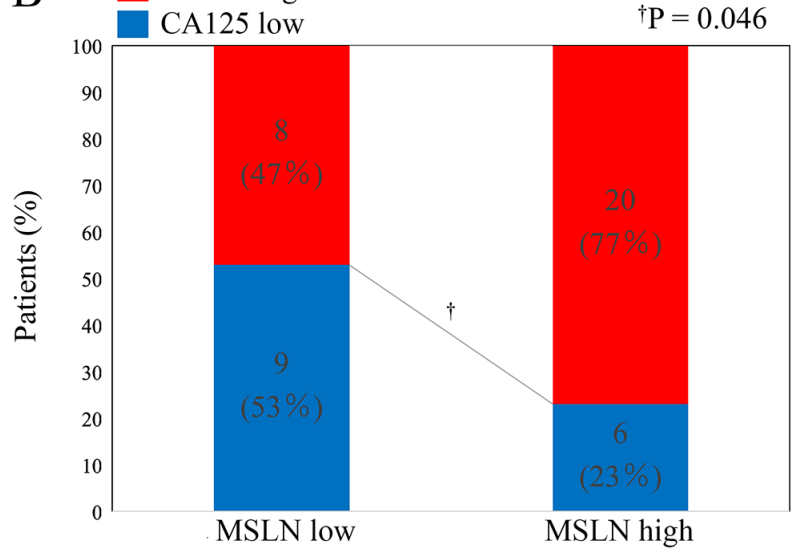

Figure 2. Association between MSLN and CA125 expression in (A) perihilar or (B) distal bile duct carcinoma tissues. MSLN, mesothelin; CA125, cancer antigen 125 .
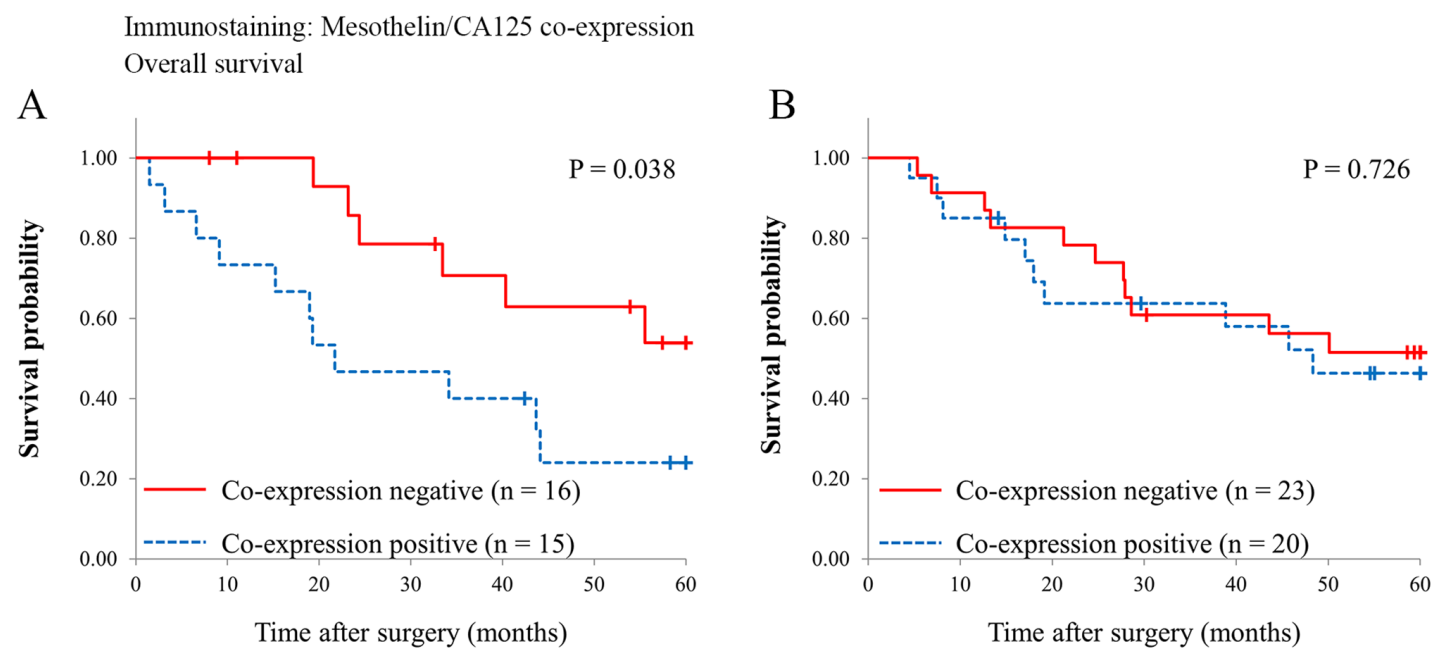

Figure 3. Comparison of overall survival between patients with (A) perihilar and (B) distal bile duct carcinoma with and without co-expression of mesothelin and cancer antigen 125 . 
Table II. Clinicopathological features of patients with perihilar bile duct carcinoma according to the expression levels of MSLN and CA125.

\begin{tabular}{|c|c|c|c|c|c|c|c|c|c|}
\hline \multirow[b]{2}{*}{ Parameter } & \multicolumn{3}{|c|}{ MSLN expression } & \multicolumn{3}{|c|}{ CA125 expression } & \multicolumn{3}{|c|}{ Co-expression } \\
\hline & $\begin{array}{l}\text { High level } \\
\quad(n=21)\end{array}$ & $\begin{array}{l}\text { Low level } \\
\qquad(\mathrm{n}=10)\end{array}$ & P-value & $\begin{array}{l}\text { High level } \\
\quad(\mathrm{n}=18)\end{array}$ & $\begin{array}{l}\text { Low level } \\
\qquad(\mathrm{n}=13)\end{array}$ & P-value & $\begin{array}{l}\text { Positive } \\
(n=15)\end{array}$ & $\begin{array}{l}\text { Negative } \\
(n=16)\end{array}$ & P-value \\
\hline \multicolumn{10}{|c|}{ Histological classification } \\
\hline Grade $1 / 2$ & 15 & 10 & 0.074 & 13 & 12 & 0.176 & 10 & 15 & 0.072 \\
\hline Grade 3 & 6 & 0 & & 5 & 1 & & 5 & 1 & \\
\hline \multicolumn{10}{|l|}{ Type } \\
\hline Papillary-expanding & 1 & 1 & $\mathrm{NC}$ & 0 & 2 & $\mathrm{NC}$ & 0 & 2 & $\mathrm{NC}$ \\
\hline Papillary-infiltrating & 5 & 3 & & 6 & 2 & & 4 & 4 & \\
\hline Nodular-expanding & 0 & 0 & & 0 & 0 & & 0 & 0 & \\
\hline Nodular-infiltrating & 9 & 4 & & 7 & 6 & & 7 & 6 & \\
\hline Flat-expanding & 0 & 0 & & 0 & 0 & & 0 & 0 & \\
\hline Flat-infiltrating & 6 & 2 & & 5 & 3 & & 4 & 4 & \\
\hline \multicolumn{10}{|l|}{ pT stage UICC } \\
\hline pT1-2 & 9 & 7 & 0.152 & 8 & 8 & 0.347 & 6 & 10 & 0.210 \\
\hline pT3-4 & 12 & 3 & & 10 & 5 & & 9 & 6 & \\
\hline \multicolumn{10}{|l|}{ pN stage UICC } \\
\hline $\mathrm{pNO}$ & 5 & 6 & 0.060 & 3 & 8 & 0.014 & 1 & 10 & 0.002 \\
\hline pN1-2 & 16 & 4 & & 15 & 5 & & 14 & 6 & \\
\hline \multicolumn{10}{|l|}{ pStage UICC } \\
\hline pI-II & 3 & 5 & 0.048 & 2 & 6 & 0.037 & 0 & 8 & 0.002 \\
\hline pIII-IV & 18 & 5 & & 16 & 7 & & 15 & 8 & \\
\hline \multicolumn{10}{|l|}{ Lymphatic permeation } \\
\hline Positive & 20 & 9 & 0.548 & 18 & 11 & 0.168 & 15 & 14 & 0.258 \\
\hline Negative & 1 & 1 & & 0 & 2 & & 0 & 2 & \\
\hline \multicolumn{10}{|c|}{ Blood vessel permeation } \\
\hline Positive & 19 & 9 & 0.704 & 18 & 10 & 0.064 & 15 & 13 & 0.125 \\
\hline Negative & 2 & 1 & & 0 & 3 & & 0 & 3 & \\
\hline \multicolumn{10}{|l|}{ Neural invasion } \\
\hline Positive & 19 & 9 & 0.704 & 18 & 10 & 0.064 & 15 & 13 & 0.125 \\
\hline Negative & 2 & 1 & & 0 & 3 & & 0 & 3 & \\
\hline \multicolumn{10}{|l|}{ Residual tumor } \\
\hline R0 & 9 & 3 & 0.390 & 6 & 6 & 0.470 & 6 & 6 & 0.886 \\
\hline $\mathrm{R} 1$ & 12 & 7 & & 12 & 7 & & 9 & 10 & \\
\hline \multicolumn{10}{|l|}{ Recurrence } \\
\hline Yes & 6 & 5 & 0.221 & 14 & 6 & 0.076 & 11 & 9 & 0.269 \\
\hline No & 15 & 5 & & 4 & 7 & & 4 & 7 & \\
\hline
\end{tabular}

Data analyzed via Fisher's exact test (for parameters with expected values of $<5$ in $>20 \%$ of cells) or $\chi^{2}$ test. MSLN, mesothelin; CA125, cancer antigen 125; UICC, Union for International Cancer Control; pT stage, pathological tumor stage; pN stage, pathological lymph node stage; $\mathrm{NC}$, not calculated.

These results suggest that co-expression of MSLN and CA125 plays a significant role in the acquisition of cell motility and invasive properties (13). The relation between MSLN expression and neural invasion in extrahepatic BDC was evaluated by previous study (16). They reported that MSLN expression did not associate with neural invasion. In this study, CA125 expression was more associated with the neural invasion than MSLN expression in perihilar and distal BDC. These findings imply that CA125 promotes neural invasion in perihilar and distal $\mathrm{BDC}$, although it remains necessary to clarify the biological function of CA125 expression in vitro and in vivo studies.

A recent study by Ishida et al (26) reported that low expression of MUC5AC and MUC6 predicts poor prognosis in patients with perihilar BDC but not in those with distal 
Table III. Clinicopathological features of patients with distal bile duct carcinoma according to the expression levels of MSLN and CA125.

\begin{tabular}{|c|c|c|c|c|c|c|c|c|c|}
\hline \multirow[b]{2}{*}{ Parameter } & \multicolumn{3}{|c|}{ MSLN expression } & \multicolumn{3}{|c|}{ CA125 expression } & \multicolumn{3}{|c|}{ Co-expression } \\
\hline & $\begin{array}{l}\text { High level } \\
\quad(n=26)\end{array}$ & $\begin{array}{l}\text { Low level } \\
\qquad(\mathrm{n}=17)\end{array}$ & P-value & $\begin{array}{l}\text { High level } \\
\quad(\mathrm{n}=28)\end{array}$ & $\begin{array}{l}\text { Low level } \\
\quad(n=15)\end{array}$ & P-value & $\begin{array}{l}\text { Positive } \\
(\mathrm{n}=20)\end{array}$ & $\begin{array}{l}\text { Negative } \\
(n=23)\end{array}$ & P-value \\
\hline \multicolumn{10}{|c|}{ Histological classification } \\
\hline Grade $1 / 2$ & 20 & 14 & 0.489 & 21 & 13 & 0.315 & 15 & 19 & 0.405 \\
\hline Grade 3 & 6 & 3 & & 7 & 2 & & 5 & 4 & \\
\hline \multicolumn{10}{|l|}{ Type } \\
\hline Papillary-expanding & 2 & 2 & $\mathrm{NC}$ & 1 & 3 & $\mathrm{NC}$ & 1 & 3 & $\mathrm{NC}$ \\
\hline Papillary-infiltrating & 14 & 2 & & 12 & 4 & & 11 & 5 & \\
\hline Nodular-expanding & 0 & 1 & & 0 & 1 & & 0 & 1 & \\
\hline Nodular-infiltrating & 7 & 7 & & 10 & 4 & & 5 & 9 & \\
\hline Flat-expanding & 0 & 0 & & 0 & 0 & & 0 & 0 & \\
\hline Flat-infiltrating & 3 & 5 & & 5 & 3 & & 3 & 5 & \\
\hline \multicolumn{10}{|l|}{ pT stage UICC } \\
\hline pT1-2 & 20 & 15 & 0.304 & 28 & 11 & 0.212 & 16 & 19 & 0.566 \\
\hline pT3-4 & 6 & 2 & & 4 & 4 & & 4 & 4 & \\
\hline \multicolumn{10}{|l|}{ pN stage UICC } \\
\hline $\mathrm{pNO}$ & 8 & 8 & 0.280 & 8 & 8 & 0.109 & 6 & 10 & 0.362 \\
\hline $\mathrm{pN} 1-2$ & 18 & 9 & & 20 & 7 & & 14 & 13 & \\
\hline \multicolumn{10}{|l|}{ pStage UICC } \\
\hline pI-II & 21 & 12 & 0.440 & 22 & 11 & 0.488 & 16 & 17 & 0.459 \\
\hline pIII-IV & 5 & 5 & & 6 & 4 & & 4 & 6 & \\
\hline \multicolumn{10}{|l|}{ Lymphatic permeation } \\
\hline Positive & 24 & 13 & 0.155 & 26 & 11 & 0.099 & 18 & 19 & 0.403 \\
\hline Negative & 2 & 4 & & 2 & 4 & & 2 & 4 & \\
\hline \multicolumn{10}{|c|}{ Blood vessel permeation } \\
\hline Positive & 25 & 14 & 0.163 & 27 & 12 & 0.114 & 19 & 20 & 0.359 \\
\hline Negative & 1 & 3 & & 1 & 3 & & 1 & 3 & \\
\hline \multicolumn{10}{|l|}{ Neural invasion } \\
\hline Positive & 26 & 14 & 0.055 & 28 & 12 & 0.037 & 20 & 20 & 0.144 \\
\hline Negative & 0 & 3 & & 0 & 3 & & 0 & 3 & \\
\hline \multicolumn{10}{|l|}{ Residual tumor } \\
\hline $\mathrm{R} 0$ & 17 & 11 & 0.964 & 18 & 10 & 0.876 & 13 & 15 & 0.988 \\
\hline $\mathrm{R} 1$ & 9 & 6 & & 10 & 5 & & 7 & 8 & \\
\hline \multicolumn{10}{|l|}{ Recurrence } \\
\hline Yes & 11 & 9 & 0.494 & 12 & 8 & 0.512 & 8 & 12 & 0.425 \\
\hline No & 15 & 8 & & 16 & 7 & & 12 & 11 & \\
\hline
\end{tabular}

Data analyzed via Fisher's exact test (for parameters have expected values of $<5$ in $>20 \%$ of cells) or $\chi^{2}$ test. MSLN, mesothelin; CA125, cancer antigen 125; UICC, Union for International Cancer Control; pT stage, pathological tumor stage; pN stage, pathological lymph node stage; $\mathrm{NC}$, not calculated.

BDC. Their results suggest that the role of MUC5AC expression might differ between perihilar and distal BDC. Our results similarly suggest that the role of MSLN and CA125 co-expression differs according to the location of BDC. The embryological origin of perihilar and distal bile duct is the same, but the environment is different. Most of the distal bile duct is located in the pancreatic parenchyma, whereas the perihilar bile duct is partially surrounded by the liver, hepatic artery, and portal vein. The differences in tumor environment might influence the invasion process and biological function of the MSLN and CA125 co-expression. Furthermore, the genomic spectra of BDC differs according to the anatomical location, such as intrahepatic bile duct, extrahepatic bile duct, or gallbladder (27). Genomic changes in the tumor might 
influence the signaling pathway controlled by the co-expression of MSLN and CA125. Genomic analysis of perihilar or distal BDC may reveal the factors affecting the signaling pathway induced by MSLN and CA125 co-expression.

Limitations of this study include its retrospective nature and that it was conducted in a single facility with a relatively small number of patients. However, to the best of our knowledge, this was the first study evaluating the association of MSLN and CA125 expression with clinicopathological features of extrahepatic BDC by focusing on the differences in tumor location. Our data should contribute to a better understanding of the clinicopathological role of MSLN-CA125 co-expression in perihilar or distal BDC. Another prospective multicenter trial is needed to confirm the effectiveness of MSLN and CA125 expression in the prediction of patient survival in perihilar and distal BDC.

In conclusion, MSLN and CA125 co-expression was associated with advanced tumor stage and poor prognosis in patients with perihilar BDC but not in those with distal BDC, which suggests that the role of co-expression in BDC differs depending on the location of the tumor.

\section{Acknowledgements}

The authors would like to thank Dr Nicole Clarke for editing a draft of this manuscript.

\section{Funding}

The present study was supported in part by the Japan Society for the Promotion of Science KAKENHI (grant no. JP 18K15295).

\section{Availability of data and materials}

The datasets used and/or analyzed during the current study are available from the corresponding author on reasonable request.

\section{Authors' contributions}

YT, TE, KK, TS, NY, IF, TT, YY, TI, YM, ES, HT, HU and YK analyzed and interpreted the patient data regarding the bile duct carcinoma, the surgical procedure and the prognosis. YT, YY, TE and SO performed the histological examination of the BDC tissues. YT was a major contributor in writing the manuscript. TE, HU and YK confirmed the authenticity of all the raw data. All authors read and approved the final manuscript.

\section{Ethics approval and consent to participate}

The present study was performed in accordance with the Declaration of Helsinki and was approved by the institutional review board of the National Defense Medical College (Tokorozawa, Japan; approval no. 4115). All patients agreed to participate in this study, and written informed consent was obtained from all patients.

\section{Patient consent for publication}

Not applicable.

\section{Competing interests}

The authors declare that they have no competing interests.

\section{References}

1. Brierley JD, Gospodarowicz MK and Wittekind C (eds): Digestive system tumours. In: TNM Classification of Malignant Tumours. 8th edition. Wiley-Blackwell, Oxford, pp83-90, 2017.

2. Rizvi S and Gores GJ: Pathogenesis, diagnosis, and management of cholangiocarcinoma. Gastroenterology 145: 1215-1229, 2013.

3. Hoyos S, Navas MC, Restrepo JC and Botero RC: Current controversies in cholangiocarcinoma. Biochim Biophys Acta Mol Basis Dis 1864: 1461-1467, 2018.

4. Khan SA, Tavolari S and Brandi G: Cholangiocarcinoma: Epidemiology and risk factors. Liver Int 39 (Suppl 1): 19-31, 2019.

5. Matsukuma S, Tokumitsu Y, Shindo Y, Matsui H and Nagano H: Essential updates to the surgical treatment of biliary tract cancer. Ann Gastroenterol Surg 3: 378-389, 2019.

6. Chang K, Pai LH, Pass H, Pogrebniak HW, Tsao MS, Pastan I and Willingham MC: Monoclonal antibody K1 reacts with epithelial mesothelioma but not with lung adenocarcinoma. Am J Surg Pathol 16: 259-268, 1992.

7. Chang K and Pastan I: Molecular cloning of mesothelin, a differentiation antigen present on mesothelium, mesotheliomas, and ovarian cancers. Proc Natl Acad Sci USA 93: 136-140, 1996.

8. Argani P, Iacobuzio-Donahue C, Ryu B, Rosty C, Goggins M, Wilentz RE, Murugesan SR, Leach SD, Jaffee E, Yeo CJ, et al: Mesothelin is overexpressed in the vast majority of ductal adenocarcinomas of the pancreas: Identification of a new pancreatic cancer marker by serial analysis of gene expression (SAGE). Clin Cancer Res 7: 3862-3868, 2001.

9. Ordóñez NG: Application of mesothelin immunostaining in tumor diagnosis. Am J Surg Pathol 27: 1418-1428, 2003.

10. Ho M, Hassan R, Zhang J, Wang QC, Onda M, Bera T and Pastan I: Humoral immune response to mesothelin in mesothelioma and ovarian cancer patients. Clin Cancer Res 11: 3814-3820, 2005.

11. Einama T, Kamachi H, Nishihara H, Homma S, Kanno H, Takahashi K, Sasaki A, Tahara M, Okada K, Muraoka S, et al: Co-expression of mesothelin and CA125 correlates with unfavorable patient outcome in pancreatic ductal adenocarcinoma. Pancreas 40: 1276-1282, 2011.

12. Hassan R, Bera T and Pastan I: Mesothelin: A new target for immunotherapy. Clin Cancer Res 10: 3937-3942, 2004.

13. Rump A, Morikawa Y, Tanaka M, Minami S, Umesaki N, Takeuchi $\mathrm{M}$ and Miyajima A: Binding of ovarian cancer antigen CA125/MUC16 to mesothelin mediates cell adhesion. J Biol Chem 279: 9190-9198, 2004.

14. Kaneko O, Gong L, Zhang J, Hansen JK, Hassan R, Lee B and Ho M: A binding domain on mesothelin for CA125/MUC16. J Biol Chem 284: 3739-3749, 2009.

15. Gubbels JAA, Belisle J, Onda M, Rancourt C, Migneault M, Ho M, Bera TK, Connor J, Sathyanarayana BK, Lee B, et al: Mesothelin-MUC16 binding is a high affinity, N-glycan dependent interaction that facilitates peritoneal metastasis of ovarian tumors. Mol Cancer 5: 50, 2006.

16. Kawamata F, Kamachi H, Einama T, Homma S, Tahara M, Miyazaki M, Tanaka S, Kamiyama T, Nishihara H, Taketomi A, et al: Intracellular localization of mesothelin predicts patient prognosis of extrahepatic bile duct cancer. Int J Oncol 41: 2109-2118, 2012.

17. Nomura R, Fujii H, Abe M, Sugo H, Ishizaki Y, Kawasaki S and Hino O: Mesothelin expression is a prognostic factor in cholangiocellular carcinoma. Int Surg 98: 164-169, 2013.

18. He X, Wang L, Riedel H, Wang K, Yang Y, Dinu CZ and Rojanasakul Y: Mesothelin promotes epithelial-to-mesenchymal transition and tumorigenicity of human lung cancer and mesothelioma cells. Mol Cancer 16: 63, 2017.

19. Einama T, Homma S, Kamachi H, Kawamata F, Takahashi K, Takahashi N, Taniguchi M, Kamiyama T, Furukawa H, Matsuno Y, et al: Luminal membrane expression of mesothelin is a prominent poor prognostic factor for gastric cancer. $\mathrm{Br} \mathrm{J}$ Cancer 107: 137-142, 2012.

20. Kawamata F, Homma S, Kamachi H, Einama T, Kato Y, Tsuda M, Tanaka S, Maeda M, Kajino K, Hino O, et al: C-ERC/mesothelin provokes lymphatic invasion of colorectal adenocarcinoma. J Gastroenterol 49: 81-92, 2014. 
21. Wang J, Bo X, Nan L, Wang CC, Gao Z, Suo T, Ni X, Liu H, Lu P, Wang Y, et al: Landscape of distant metastasis mode and current chemotherapy efficacy of the advanced biliary tract cancer in the United States, 2010-2016. Cancer Med 9: 1335-1348, 2020.

22. Hasebe T, Konishi M, Iwasaki M, Endoh Y, Nakagohri T, Takahashi S, Kinoshita T and Ochiai A: Histological characteristics of tumor cells and stromal cells in vessels and lymph nodes are important prognostic parameters of extrahepatic bile duct carcinoma: A prospective study. Hum Pathol 36: 655-664, 2005.

23. Noji T, Miyamoto M, Kubota KC, Shinohara T, Ambo Y, Matsuno Y, Kashimura N, Hirano S: Evaluation of extra capsular lymph node involvement in patients with extra-hepatic bile duct cancer. World J Surg Oncol 10: 106, 2012.

24. Shimizu A, Hirono S, Tani M, Kawai M, Okada K, Miyazawa M, Kitahata Y, Nakamura Y, Noda T, Yokoyama S, et al: Coexpression of MUC16 and mesothelin is related to the invasion process in pancreatic ductal adenocarcinoma. Cancer Sci 103: 739-746, 2012
25. Chen SH, Hung WC, Wang P, Paul C and Konstantopoulos K: Mesothelin binding to CA125/MUC16 promotes pancreatic cancer cell motility and invasion via MMP-7 activation. Sci Rep 3: 1870, 2013.

26. Ishida K, Osakabe M, Eizuka M, Tai S, Sugimoto R, Fujita Y, Katagiri H, Takahara T, Uesugi N, Nitta H, et al: The expression of gastrointestinal differentiation markers in extrahepatic cholangiocarcinoma: Clinicopathological significance based on tumor location. Hum Pathol 92: 91-100, 2019.

27. Nakamura H, Arai Y, Totoki Y, Shirota T, Elzawahry A, Kato M, Hama N, Hosoda F, Urushidate T, Ohashi S, et al: Genomic spectra of biliary tract cancer. Nat Genet 47: 1003-1010, 2015.

c) (i) $\Theta$ This work is licensed under a Creative Commons Attribution-NonCommercial-NoDerivatives 4.0 International (CC BY-NC-ND 4.0) License. 